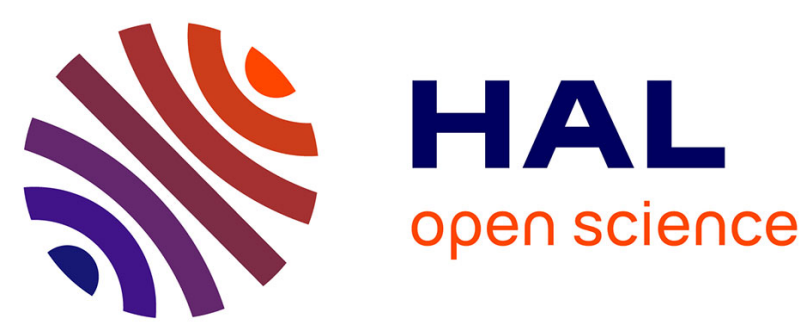

\title{
CALORIMETRIC INVESTIGATION OF THE MARTENSITIC TRANSFORMATION IN NEAR STOICHIOMETRIC AND STOICHIOMETRIC Fe3Pt AND SHAPE MEMORY EFFECT
}

N. Matveeva, G. Demensky, L. Petrov, Yu. Kovneristyi, O. Teplov

\section{To cite this version:}

N. Matveeva, G. Demensky, L. Petrov, Yu. Kovneristyi, O. Teplov. CALORIMETRIC INVESTIGATION OF THE MARTENSITIC TRANSFORMATION IN NEAR STOICHIOMETRIC AND STOICHIOMETRIC Fe3Pt AND SHAPE MEMORY EFFECT. Journal de Physique Colloques, 1982, 43 (C4), pp.C4-377-C4-382. 10.1051/jphyscol:1982455 . jpa-00222171

HAL Id: jpa-00222171

https://hal.science/jpa-00222171

Submitted on 1 Jan 1982

HAL is a multi-disciplinary open access archive for the deposit and dissemination of scientific research documents, whether they are published or not. The documents may come from teaching and research institutions in France or abroad, or from public or private research centers.
L'archive ouverte pluridisciplinaire HAL, est destinée au dépôt et à la diffusion de documents scientifiques de niveau recherche, publiés ou non, émanant des établissements d'enseignement et de recherche français ou étrangers, des laboratoires publics ou privés. 
JOURNAL DE PHYSIQUE

CozZoque C4, supplément au $n^{\circ}$ 12, Tome 43, décembre 1982

page $\quad \mathbf{C} 4-377$

CALORIMETRIC INVESTIGATION OF THE MARTENSITIC TRANSFORMATION IN NEAR STOICHIOMETRIC AND STOICHIOMETRIC $\mathrm{Fe}_{3} \mathrm{Pt}_{\mathrm{t}}$ AND SHAPE MEMORY EFFECT

\author{
N.M. Matveeva, G.K. Demensky, L.A. Petrov, Yu.K. Kovneristyi and O.A. \\ Teplov \\ A.A. Baikov Institute of Metallurgy, Academy of Sciences, Moscow, U.S.S.R. \\ (Accepted 9 August 1982)
}

\begin{abstract}
Heats and temperatures of the $\gamma \vec{\rightleftarrows} \alpha$ martensitic transformation in the $F e_{3} P t$ alloy have been measured after quenching and annealing at $820 \mathrm{~K}$. The results obtained are discussed in terms of heterogeneous atomic ordering $\mathrm{AI} \rightarrow \mathrm{II}_{2}$ and eutectoid decomposition $\gamma \rightarrow \alpha+\mathrm{Fe}_{3} \mathrm{Pt}$, which occur during annealing and preceed the martensitic transformation.
\end{abstract}

Introduction.- Alloys of the Fe-Pt system close to the Fe Pt composition undergo a $\gamma \rightleftarrows \alpha$ martensitic transformation, being of particular interest, since properties of the martensite are governed by the other phase transformations, rival to the martensitic one. So the maxtensitic transformation of rapidly quenched alloys is not thermoelastic and is accompanied by a significant thermal hysteresis. When the martensitic transformation is preceeded by the atomic ordering $\mathrm{AI} \rightarrow \mathrm{II}_{2}$ it becomes a thermoelastic one and has a small thermal hysteresis. The alloys are capable of recovering their shape. The effect of atomic ordering on the martensitic transformation in the iron-base alloys with 23-27\% Pt has been discussed often /I-7/. Various criteria were proposed to determine the thermoelasticity of transformation. Accoraing to /I/ the major criterion is given by some level of the $M_{s}$ point, depending on the degree of the long-range ordering, which should necessarily be below the curie point. This level determines a small thermal hysteresis of transformation, certain tetragonality of the $\gamma$ - and $\alpha$-phases, enhancing crystallographic rearrangement, and small volume change during the $\gamma \rightleftharpoons \alpha$ transformation. one of the important properties of the thermoelastic transformation is its small driving force as compared to that of the non-thermoelastic one $/ 8 /$. It oan be expressed in terms of the heat effect and the transformation temperature /9-II/. The latent heat of the $\gamma-\alpha$ transformation in $\mathrm{Fe}-24.5 \mathrm{Pt}$ alloy is determined in one study /I2/. It gives the value of $\Delta \mathrm{H} \gamma \rightarrow \alpha$ for the two ultimate conditions, disordered and annealed at $820 \mathrm{~K}$ for I20 hrs.

The present study is aimed at the calorimetric determination of the heat effects of the $\gamma=\alpha$ transformation in the quenched Fe-24 Pt and $\mathrm{Fe}-25 \mathrm{Pt}$ alloys and at the process of atomic ordering at $820 \mathrm{~K}$. The results obtained should be evaluated in connection with the processes occuring in alloys during annealing. The study also deals with the temperature dependence of deformation in order to establish the shape memory effect.

Experimental results. - The alloys were prepared by the method of levitatian melting in helium and cast into a cylindrical mould. Ihis 
was followed by a solution treatment at $1373 \mathrm{~K}$ for 24 hrs and by water quenching from $1473 \mathrm{~K}$. The ingots were cut into cylindrical specimens $5 \times 8 \mathrm{~mm}$ for calorimetry and wire specimens $I \mathrm{~mm}$ in dm for the study of deformation. Capability of allogs to the shape memory effect was determined on wires under torsion deformation. The phase composition was determined by $\mathrm{X}$-Ray analysis. The Fe-24 Pt and Fe-25 Pt alloys consist of two phases $\alpha+\gamma$ after quenching, therefore before calorimetric study they were cooled down in liquid nitrogen in order to ascribe the heat effect to the full $\gamma \rightleftharpoons \alpha$ transformation. The heat effects were measured in a DSC-III Setaram calorimeter /3/. The error of the enthalpy determination was about $3 \%$. The effect was separated from the zero Iine by the Berg method. The experiment was carried out as follows: the specimen was heated in the calorimeter up to $820 \mathrm{~K}$, held at this temperature for some time and then cooled down to I50 $\mathrm{K}$. Thereby one cycle included annealing-cooling-heating. A direct transformation proceeds rapidly, in time, being of the same order as the calorimeter constant $\left(\tau_{c}=30 \mathrm{~s}\right)$, therefore the $\mathbf{m}_{s}$ and $u_{f}$

points were taken at the beginning and maximum of the heat effect respectively. The reverse $\alpha-\gamma$ transformation is delayed, its duration is more than $\tau_{c}$, thexefore the points $A_{s}$ and $A_{f}$ are taken at the beginning and end of the peak respectively. Table I sums up the data on temperatures and heats of the $\gamma \neq \alpha$ transformation after several cyoles of heating and cooling and short-time annealing at $820 \mathrm{~K} d i-$ rectly in the calorimeter. Fig.I shows the heating curves of the Fe-25 Pt alloy for several cycles. The heating curves exhibit at least two effects for the reverse $\alpha \rightarrow \gamma$ transformation. Their values reduce, as is also the case for those of the $\gamma \rightarrow \alpha$ transformation. The $A_{s}$ points of the first effect (I) reduce with the increase of the annealing duration, point $A_{s}$ of the second effect (II) does not change until the effect ceases after 6 hrs of annealing. The heat effects of the $\gamma-\alpha$ transformation are individual and of sharp shape, corresponding to the high rate of the $\gamma-\alpha$ transformation. After II. 5 hrs of annealing the heat effect of the $\alpha-\gamma$ transformation is strongIy smeared, it can hardly be separated from the zexo line and precise$1 y$ measured. The heat effect of the $\gamma \rightarrow \alpha$ transformation is small (about $150 \mathrm{~J} / \mathrm{mole}$ ) and it is proportional to the driving force of the thermoelastio martensitic transformation of this alloy. In the Fe-24 Pt alloy the heat effects of the $\alpha \rightarrow \gamma$ transformation divide into two after $2 \mathrm{hrs}$ of annealing at $820 \mathrm{~K}$, while sharp reduction of the $\Delta \mathrm{H}$ value of the $\gamma=\alpha$ transformation also occurs in the first cycles at the constant points of transformation. After 5 hrs of annealing the heat effect II at $650 \mathrm{~K}$ disappears, while the first one (I) observed at lower temperatures is smeared. Fig.2 shows the time dependence of the temperatures and heats of the $\gamma=\alpha$ transformation. Fig. 3 shows the temperature dependence of deformation for the Fe-24 Pt and Fe-25 Pt alloys after annealing at various temperatures and holding times. The quenched alloys do not exhibit any noticeable shape memory effect. The Fe-25 Pt alloy (Fig.3a), annealed for 4 hrs at $820 \mathrm{~K}$, recovers the accumulated strain energy over a wide temperature range, the process being noticeably two-stage and incomplete. After annealing for $20 \mathrm{hrs}$ this alloy (Fig. $3 \mathrm{~b}$ ) does not undergo martensitic transformation down to $77 \mathrm{~K}$. For Fe-24 Pt alloy (Fig.3c), annealed for 24 hrs, complete recovery is observed on heating over the range of 175 $300 \mathrm{~K}$. After annealing for $48 \mathrm{brs}$ at $873 \mathrm{~K}$ this range reduces down to 77-170 K. Degree of the long-range order in the Fe-24 Pt alloy is not high after heat-treatments described and is about 0,6 and 0,7 respectively. 
Table I.

\begin{tabular}{|c|c|c|c|c|c|c|c|c|c|}
\hline \multirow{2}{*}{$\begin{array}{l}\text { Cycle } \\
\mathrm{Nr}\end{array}$} & \multirow{2}{*}{$\begin{array}{l}\text { Tlme } \\
\text { of an- } \\
\text { neal- } \\
\text { ing at } \\
820 \mathrm{~K} \text {, } \\
\text { (hrs) }\end{array}$} & \multirow{2}{*}{$M_{s}, K$} & \multirow{2}{*}{$M_{f}, \mathrm{~K}$} & \multirow{2}{*}{$A_{s}, K$} & \multirow{2}{*}{$A_{f}, K$} & \multicolumn{2}{|c|}{$\Delta H \quad \gamma-\alpha$} & \multicolumn{2}{|c|}{$\Delta \mathrm{H} \quad \alpha \rightarrow \gamma$} \\
\hline & & & & & & cal/g & $\mathrm{J} / \mathrm{mole}$ & $\mathrm{cal} / \mathrm{g}$ & $J /$ mole \\
\hline
\end{tabular}

25 at $\mathrm{Pt}$

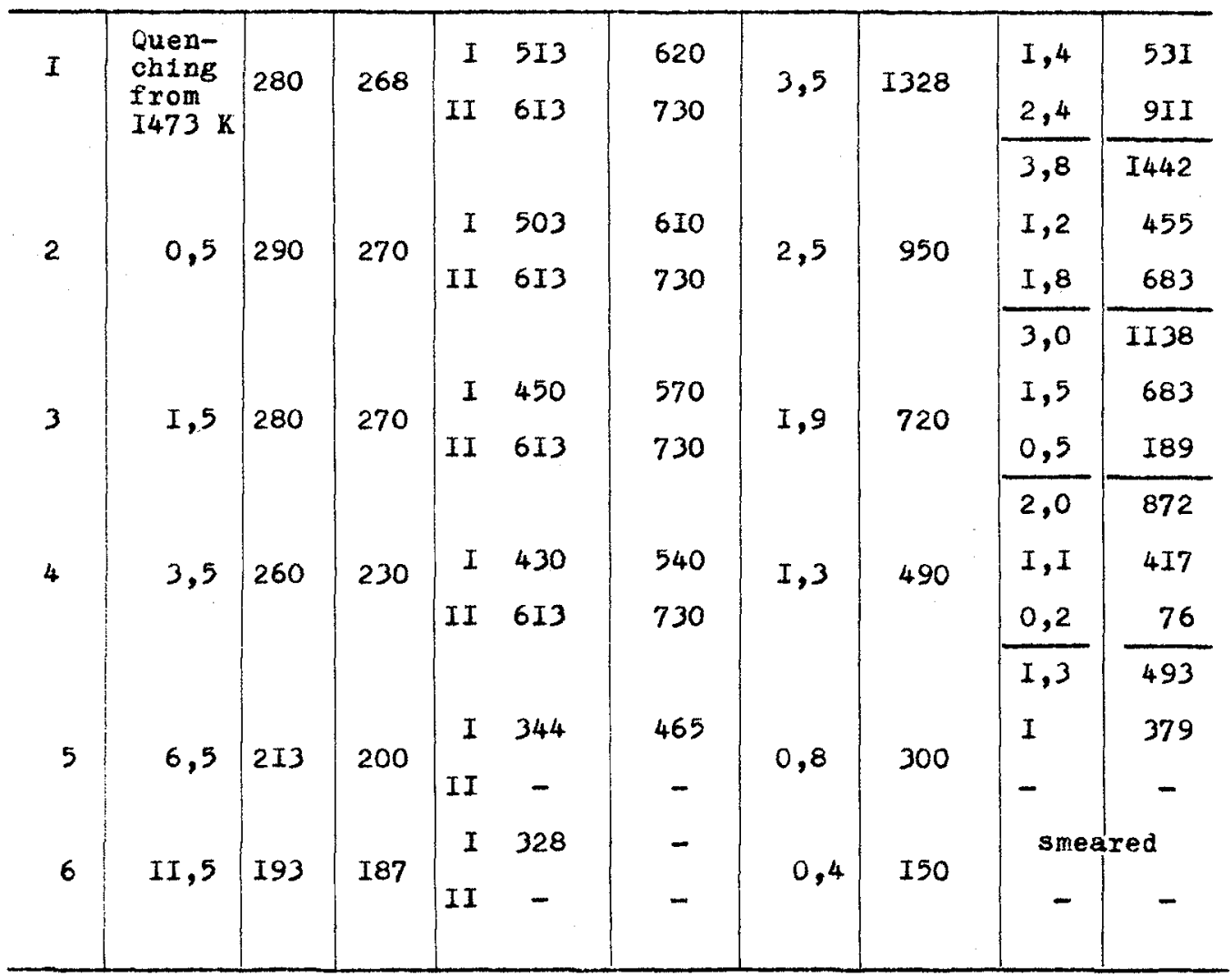

24 at $\% \mathrm{Pt}$

\begin{tabular}{|c|c|c|c|c|c|c|c|c|c|c|}
\hline I & $\begin{array}{l}\text { Quen- } \\
\text { ching } \\
\text { from } \\
\text { I473 K }\end{array}$ & - & - & & 650 & 770 & - & - & 6,5 & 2428 \\
\hline 2 & 0,5 & 332 & 316 & & 655 & 760 & 4,8 & 1793 & 3,6 & 1345 \\
\hline 3 & $I, O$ & 310 & $29 I$ & & 650 & 755 & 2,0 & 747 & $I, 9$ & 710 \\
\hline \multirow[t]{2}{*}{4} & & & & $I$ & 300 & smeared & $I, 4$ & 522 & smea & red \\
\hline & IO & 250 & 240 & II & - & II - & - & & & \\
\hline
\end{tabular}



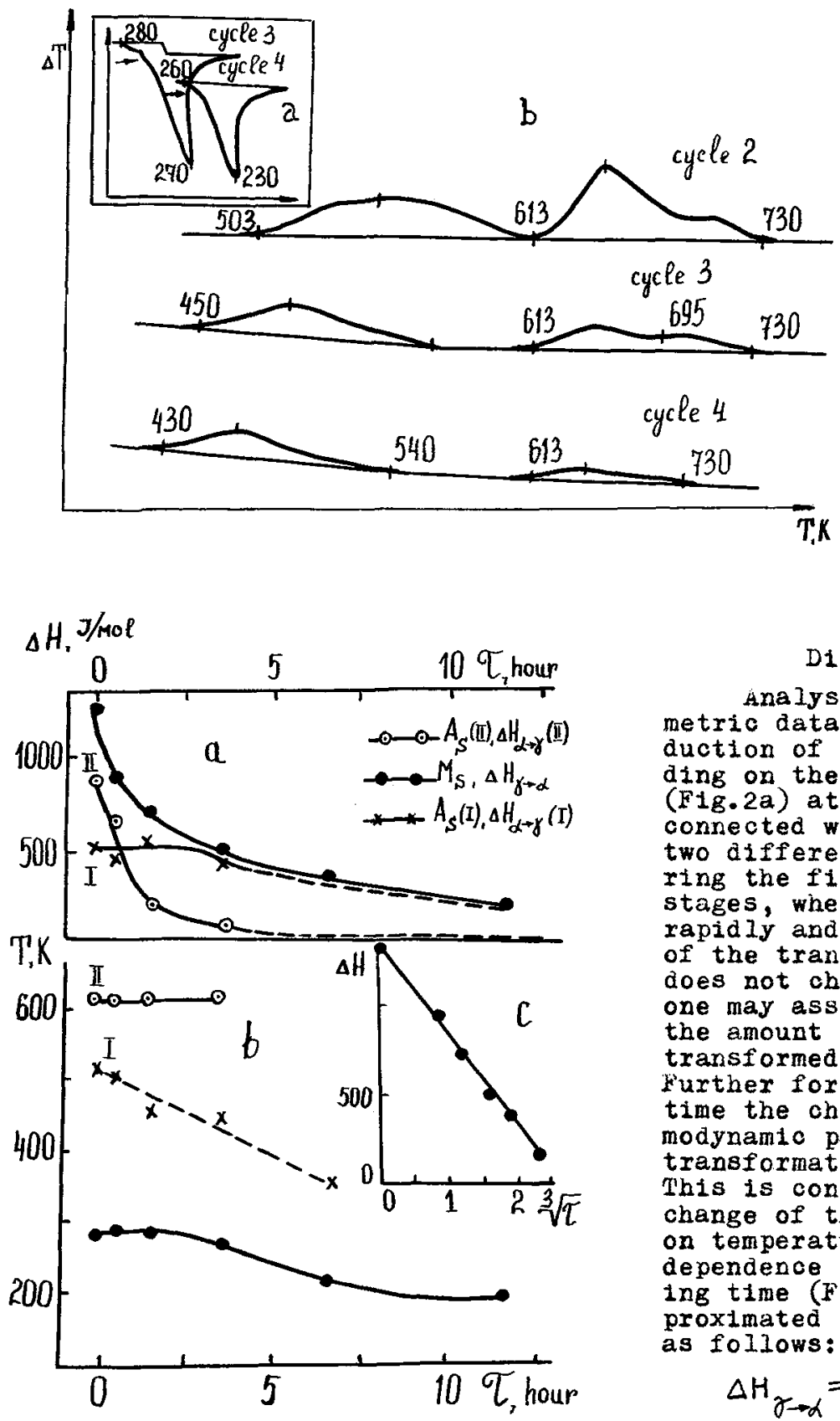

Fig.I. Heat effects of the $\gamma \rightarrow \alpha(a)$ and $\alpha \rightarrow \gamma$ (b) transformation in the $\mathrm{Fe}_{3} \mathrm{Pt}$ alloy. T.K

Fig.2, Dependence of tae heats and temperatures of the $\gamma \Leftarrow \alpha$ transformation on holding time of the annealing at $820 \mathrm{~K}$ in the $\mathrm{Fe}_{3} \mathrm{Pt}$ alloy.

\section{Discussion}

Analysis of the calorimetric data shows, that reduction of $\triangle H \gamma \rightleftharpoons \alpha$ depending on the annealing time (F1g.2a) at $820 \mathrm{~K}$ should be connected with, at least, two aifferent processes. During the first annealing stages, when $\Delta H$ decreases rapidly and the temperature of the transformation start does not change (Fig.2b), one may assume, that only the amount of the phase transformed is decreased. Further for louger annealing time the change of the thermodynamic parameters of transformation is possible. This is confirmed by the change of the transformation temperature (Fig.2b). The dependence of $\mathrm{H}$ on annealIng time (Fig.2c) may be approxlmated by the equation as follows:

$$
\Delta H_{\gamma \rightarrow \alpha}=K \sqrt[3]{\tau}+\Delta H_{\tau=0}
$$

A dependence of that $\mathrm{kind}$ may arise when the decrease of the amount of phase transformed is due to diffusion 


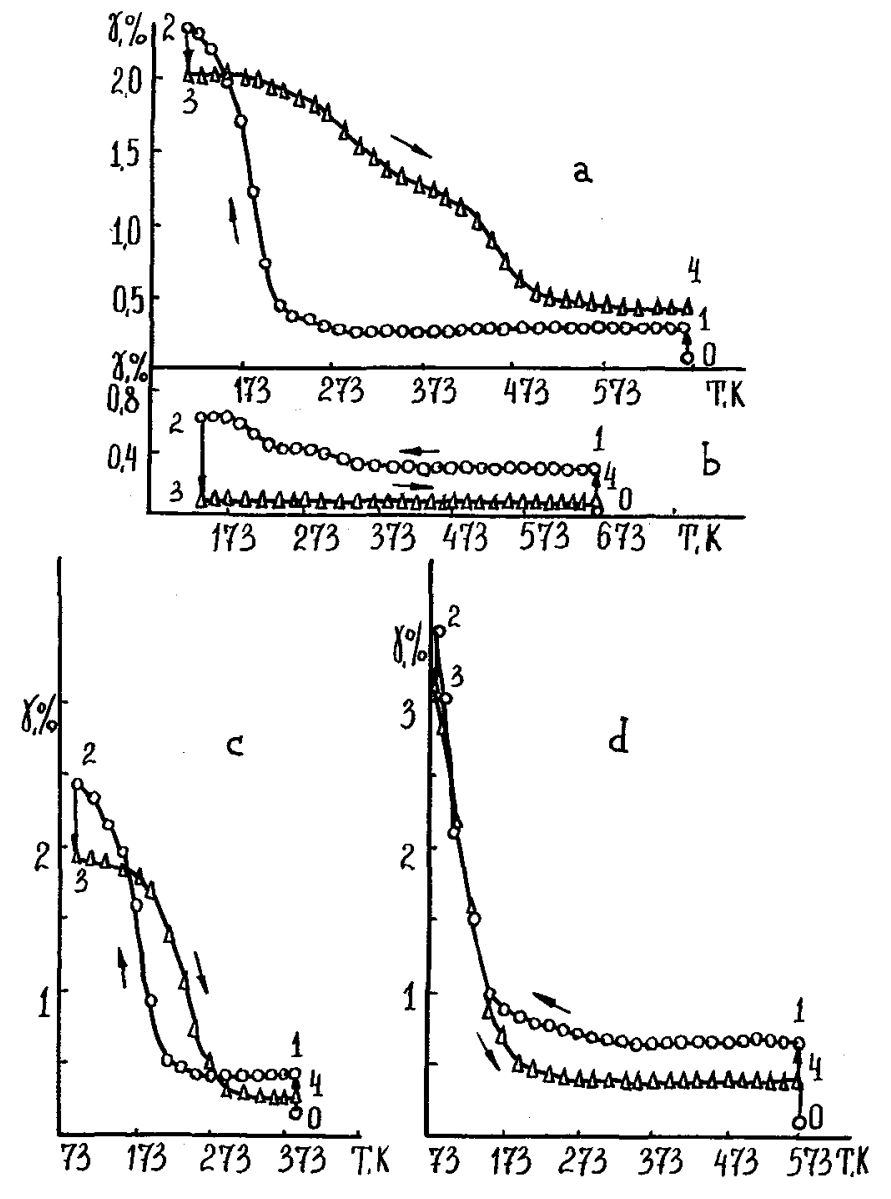

Fig.3. Temperature dependence of the deformation, $0-I$ elastic loading, I-2 accumulation of the deformation on cooling, 2-3 unloading, 3-4 recovery of the deformation on heating.

a) Fe-25 Pt alloy annealed for 4 hrs at $820 \mathrm{~K}$;

b) Fe-25 Pt alloy annealed for 20 hrs at $820 \mathrm{~K}$;

c) $\mathrm{Fe}-24^{\circ} \mathrm{Pt}$ al10 annealed for $20 \mathrm{hrs}$ at $820 \mathrm{~K}$; d) $\mathrm{Fe}-24^{\prime} \mathrm{Pt}$ a $110 \mathrm{y}$ annealed for 48 hrs at $870 \mathrm{~K}$.

processes. X-Ray data showed also the $\alpha$-phase in the alloys, annealed at $820 \mathrm{~K}$ together with partially ordered austenite. This confirms the eutectoid decomposition: $\gamma \rightarrow \alpha+$ $+\mathrm{Fe}_{3} \mathrm{Pt}$ above $820 \mathrm{~K}$, therefore the amount of the $\gamma$-phase decreases. When annealing the quenched alloys, whose concentration of thermal vacancies is high, the initial rate of eutectoid $\gamma$-phase decomposition is also high, then on cooling the decomposition is interrupted by the martensitic transformation and finally freezed down. Further on annealing, an atomic ordering is prevailing, effecting the martensitic transformation, which follows. Decrease of the $\Delta H$ - value of the $\gamma \neq \alpha$ transformation is slowing down. After annealing for IO hrs the $\triangle \mathrm{H}$ of the $\mathrm{Fe}-24 \mathrm{Ft}$ alloy decreased down to $522 \mathrm{~J} / \mathrm{mole}$; this is close to the value obtained in $/ 13 /$ ( $347 \mathrm{~J} / \mathrm{mole}$ ) for the alloy, annealed for I20 hrs.

During the isothermal annealing at $820 \mathrm{~K}$ a heterogeneous process of atomic ordering takes place. Ordered and disordered austenite are simultaneously present in the alloy. An amount of the ordered phase increases, but the heat effeot of its martensitic transformation decreases. That is why up to the fifth cycle $\Delta H \alpha \rightarrow \gamma$ (I)-transformation slightly changes in time. The presence of two maxima (I and II) in the thermal effect of the transformation, with constant temperatures of one of them (II) and with decreasing temperatures for 
the ordex (I), corresponds to the double bend in the curves of the temperature dependence of the electrical resistivity when heating the $\mathrm{Fe}_{3} \mathrm{Pt}$ alloy, as in /I/. These phenomena are, apparently, of the same origin.

Finaliy, one should bear in mind that partially ordered alloys exhibit practically complete shape memory effect. This is in accordance with the assumption /3/ that high degree of the long-range order $\mathrm{II}_{2}$ is not a determinant criterion for shape memory. The idea about the inherited nuclei of martensite in austenite at the temperatures above $A_{s}$ is not a speculative one for the Fe ${ }_{3}$ t alloy. These may be the local regions of the $\alpha$-phase, produced by the eutecto1d reaction.

Thus, isothermal annealing at $820 \mathrm{~K}$, followed by heating and cooling over the interval of the $\gamma \approx \alpha$ transformation in the alloys close to the $\mathrm{Fe}_{3} \mathrm{Pt}$ composition, results in the first cycles together with the atomic ordering $\mathrm{AI} \rightarrow \mathrm{II}_{2}$ also in the eutectoid decomposition $\gamma \alpha+\mathrm{Fe}_{3} \mathrm{Pt}$. Decrease of the $\gamma$-phase amount causes sharp reduction of the heats of the $\gamma \neq \alpha$ transformation. On further cycles the martensitic transformation is mainly influenced by heterogeneous atomic ordering. Therebs, the transformation temperatures of the $\gamma \rightarrow \alpha$ - transformation also decrease. One should also take into account the rival phase transformations, sinoe they may exert an effect on both the formation of the nucleus and on the character of the $\gamma \rightarrow \alpha$ martensitic transformation as well as on the final properties of the martensite.

\section{Keferences:}

I. Umemoto M. and Wayman C.M.: Met. Trans. 9A (I978), 89I.

2. Dunne D.P. and Wayman C.M.: Met. Trans. 4. (I973), I37.

3. Kajiwara S. and Owen W.S.: Met. Trans. $5^{-}(1974), 2047$.

4. Tadaki T. and shimizu K.: Scripta Met. $\overline{9}$ (I975), 77I.

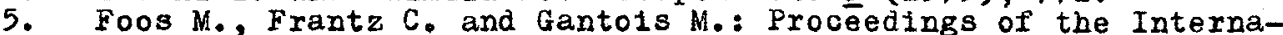
tional Conference on Martensitic Transformations. ICOMAT. Oxford USA (1979), 485.

6. A.S. Tailasher, N.M.Matveeva, I. I.Ganzina. Alloys of the Rare and Refractory Metals with Special Physical properties. Moscow, Nauka, (I979) 304 .

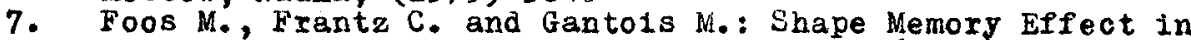
Alloys. Plenum Press New York and London (I975), 407.

8. Christian Y.M.: Proceedings of the International Conference on Martensitic Transformations. ICOMAT. Oxford USA (I979), 220.

9. Christian $Y$. M.: The The ory of Transformation, Pexgamon Press, oxford I 965 .

I0. Kovneristyi Yu.K., Belousor O.K., Fedotor S.Go and Matreeva N.M. Titanium 80 Science and Technology。 Proc. Fourth Inter.Conf. on Titanium. Kyoto, Japan, (I980) v.2, I469-8I.

II. Tong H.C. and Waymán C.M०: Acta Met. 23 (I975), 209.

I2. Tong H.C. and Wayman C.M.: Met. Trans. 5 (I974), 1945.

13. Marono R.T. Texmochim。Acta 26 (I978), 27. 